\title{
Evaluation of some markers of vigor in seedlings of Douglas fir (Pseudotsuga menziesii (Mirb.) Franco)
}

\author{
J.B. Zaerr, V.D. Hipkins and K. Forry \\ Department of Forest Science, Oregon State University, Corvallis, OR 97331, U.S.A.
}

\section{Introduction}

The timely identification of damaged seedlings or seedlings of low vigor is an important aspect of forest regeneration in the Pacific Northwestern United States. When a plantation fails because seedlings die, replanting is necessary. If damaged or seedlings of low vigor could be identified before they are planted, considerable labor savings could be realized as well as improved productivity of the forest (Cleary et al., 1982). A practical test of seedling vigor must be easy to conduct and should provide results quickly. At the present time, the root growth capacity (RGC) test is used extensively, but results require $2-4$ wk and do not always predict field survival accurately. The objective of this study was to evaluate 3 recently suggested alternative indicators of seedling vigor: the starch content of roots (Puttonen, 1986), the osmotic concentration of xylem sap and biochemical markers of seedling vigor (Duryea, 1985).

\section{Materials and Methods}

Two yr old seedlings of Douglas fir (Pseudotsuga menziesii (Mirb.) Franco) were lifted on 4 dates throughout the planting season and divided into lots of 70 seedlings for each treatment. The following treatments were applied: drying seedlings with exposed roots in a warm, dry room $\left(30^{\circ} \mathrm{C}, 30 \%\right.$ relative humidity) for 0.25 , 0.5 or $1 \mathrm{~h}$; freezing to $-9,-12$ or $-15^{\circ} \mathrm{C}$; and storage at $2^{\circ} \mathrm{C}$ for 0,2 or $4 \mathrm{mo}$. There was a total of 30 treatments. Survival in the field indicated that a wide range of survival percentages was achieved and that there were fairly well distributed intermediate values.

For each treatment, 20 seedlings were potted in soil and placed in a greenhouse for measurement of RGC (number and length of new roots after $30 \mathrm{~d}$ ), 20 were potted in soil and placed in a growth chamber $\left(21^{\circ} \mathrm{C}, 16 \mathrm{~h}\right.$ photoperiod) to measure survival and bud-burst, 20 were outplanted at a field site near Corvallis $(30 \times 30$ $\mathrm{cm}$ spacing), and 10 were used for samples of plant material. Xylem sap was extracted with a pressure charnber apparatus and the osmotic concentration of the sap was measured with an osmometer immediately. The roots were excised, steamed for 5-10 min to inactivate the native enzymes, frozen with liquid nitrogen, lyophilized and stored at $-80^{\circ} \mathrm{C}$ until analyzed for starch $(n=10)$. Starch was analyzed by the amylase/amyloglucosidase method of Haissig and Dickson (1982). The apical $2 \mathrm{~cm}$ of the shoot were excised, ground with methanol in a polytron, extracted 5 times with hexane to remove chlorophyll, dried and stored at $-80^{\circ} \mathrm{C}$ until analyzed by high performance liquid chromatography (HPLC). For analysis by HPLC, the dried sample was taken up in $1 \mathrm{ml}$ of methanol and a $25 \mu \mathrm{l}$ sample was injected into a Varian 
model 5000 HPLC fitted with a $C_{18}$ reverse phase column (Spherical ODS, $0.46 \times 2 \mathrm{~cm}$, $5 \mu \mathrm{m})$, and a Beckman 164 variable wavelength detector set at $254 \mathrm{~nm}$ in tandem with a Perkin-Elmer 650-10S fluorescence spectrophotometer (ex/em 290/360 nm). The flow rate was $1 \mathrm{ml} / \mathrm{min}$ and the solvent gradient was linear from $10 \%$ methanol in $20 \mathrm{mM}$ triethylamine acetate $(\mathrm{pH} 3.37)$ to $65 \%$ methanol at 20 min to $85 \%$ methanol at $25 \mathrm{~min}$ to $100 \%$ methanol at 27 min holding at $100 \%$ until 40 min. Data were collected with a Keithley DAS 500 connected to an IBM XT and controlled by MAXIMA software. Statistical analysis was conducted with SAS programs and included cluster analysis and stepwise discriminate analysis (Afifi and Clark, 1984).

\section{Results}

Measurements of osmotic concentration of xylem sap varied widely within treatments and between treatments. There was no apparent overall trend. For individual treatments there were no apparent trends except for seedlings which had been damaged by freezing but had not been stored. For freshly frozen seedlings, increased osmotic concentration was an indicator of low survival.

The starch content of roots increased from a low on the first lifting date (October, $2 \%$ ) to a high on the last lifting date (March, 11\%). This increase in starch content did not match the overall field survival of those plants. Root starch content was not related to survival in the growth room or to survival in the field. Even when considering the overall increase in starch content with lifting date, root starch content did not predict growth room or field survival.

Cluster analysis of the chromatography data indicated a strong effect of lifting date, but stepwise discriminate analysis was more useful in relating chromatography peaks to survival data. Of the 230 distinct peaks observed, 20 were found to be related to survival. Comparable results were obtained using either the presence or the area of peaks. Fig. 1 shows a canonical plot of field survival using peak frequency data. In this case, the discriminate analysis using 9 peaks completely separated the 3 classes of field survival. An even better separation can be achieved by using additional peaks (up to 20). If fewer peaks are used, the classes of field survival tend to overlap. Similar results were obtained when peak presence or peak area was tested against survival in the growth room or against RGC.

\section{Discussion and Conclusion}

The osmotic concentration of xylem sap is clearly a poor marker of vigor in Douglas fir seedlings except in the case of freshly frozen plants. In the latter case, osmotic concentration measurements could probably detect badly frozen seedlings (high osmotic concentration = low survival) and might be useful in situations where recent freezing damage was suspected.

The concentration of starch in roots might be used as an indicator of date of lifting, but it is not a useful indicator of plant vigor. Common sense suggests that plants low in starch might have difficulty surviving when outplanted, particularly on a harsh site. However, our data show that plants low in starch can survive, at least on some sites. Although we measured field survival, we do not yet have a measurement of growth for these seedlings. It could be that root starch content is more closely related to growth than to survival.

The chromatography data were found to be related to RGC, survival in the growth room and survival in the field. The most important relationship was that found between a small number of peaks (up to 20 


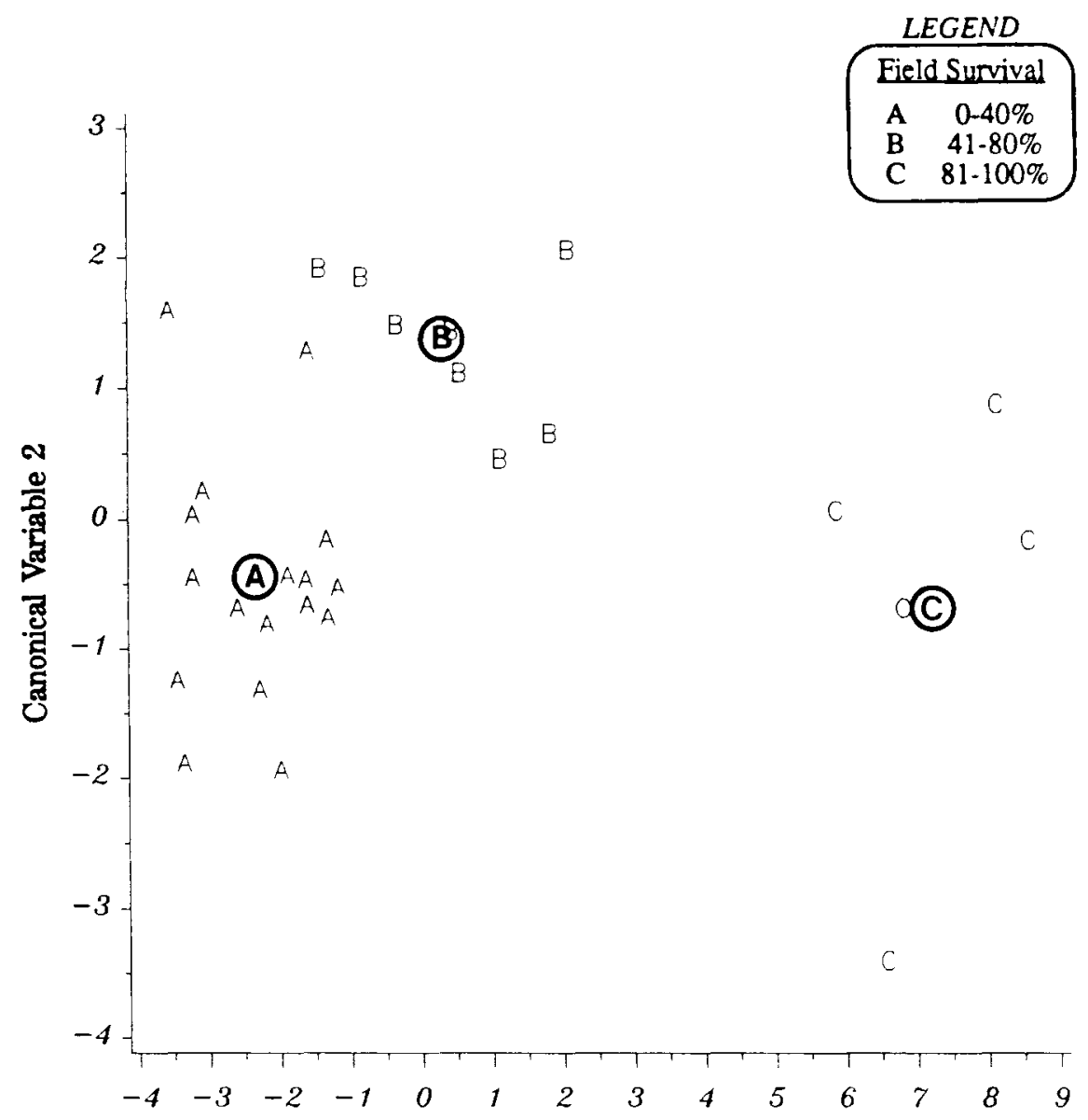

Canonical Variable 1

Fig. 1. Plot of treatment means on the first 2 canonical variables obtained by canonical discriminant analysis of peak frequency data. Groups were based on 1 yr field survival. The first canonical variable accounted for $94.32 \%$ $(P \leq 0.0001)$ of the total dispersion. Positions of the mean values of the canonical variables for each of the 3 groups are indicated in bold letters.

peaks can be used but only 9 were used in the example shown in Fig. 1) and field survival. This result implies the possibility of using a few peaks on an HPLC chromatogram to predict vigor of outplanted seedlings. Efforts are currently underway to characterize chemically the compounds suggested by this study as being predictive of vigor and to test the ability of peaks on an HPLC chromatogram to predict the vigor of outplanted seedlings. After sufficient field testing, this technique might be developed into a reliable operational method for evaluating seedling vigor. 


\section{References}

Afifi A.A. \& Clark V. (1984) In: Computer-aided Multivariate Analysis. Lifelong Learning Publications, Belmont, CA, pp. 246-286; 379-411

Cleary B.D., Greaves R.D. \& Hermann R.K. (1982) In: Regenerating Oregon's Forests. Oregon State Univ. Extension Serv., Corvallis, OR, pp. 287

Duryea M.L. (1985) In: Evaluating Seedling

Quality: Principles, Procedures, and Predictive
Abilities of Major Tests. Forest Research Laboratory, Oregon State University, Corvallis, OR, pp. 143

Haissig B. \& Dickson R.E. (1982) Glucose measurement errors in enzymatic starch hydrolysates at high enzyme-glucose weight ratios. Physiol. Plant. 54, 244-248

Puttonen P. (1986) Carbohydrate reserves in Pinus sylvestris seedling needles as an attribute of seedling vigor. Scand. J. For. Res. 1, $181-193$ 